\title{
Conductive Polymeric Composites Based on Multiwalled Carbon Nanotubes and Linseed Oil Functionalized and Cross-Linked with Diacetylenes from Propargyl Alcohol
}

\author{
Alejandro Ramírez-Jiménez, Susana Hernández-López, and Enrique Vigueras-Santiago \\ Laboratorio de Investigación y Desarrollo de Materiales Avanzados (LIDMA), Facultad de Químmica, \\ Universidad Autónoma del Estado de México, Paseo Colón Esquina con Paseo Tollocan, 50000 Toluca, MEX, Mexico
}

Correspondence should be addressed to Alejandro Ramírez-Jiménez; alejandro.ramirez@nucleares.unam.mx, Susana Hernández-López; shernandezl@uaemex.mx, and Enrique Vigueras-Santiago; enriqueviguerass@uaemex.mx

Received 5 June 2015; Accepted 11 August 2015

Academic Editor: Dan Xia

Copyright (C) 2015 Alejandro Ramírez-Jiménez et al. This is an open access article distributed under the Creative Commons Attribution License, which permits unrestricted use, distribution, and reproduction in any medium, provided the original work is properly cited.

\begin{abstract}
Diacetylene-functionalized epoxidized linseed oil (DAELO) matrix was synthesized in order to improve the dispersion of multiwalled carbon nanotubes (MWCNTs) without the necessity of some chemical or physical modification of them. That fact was evidenced by the low critical concentration of DAELO-based composites in comparison (1.0 wt\% MWCNTs) with the epoxidized linseed oil- (ELO-) based composites ( $5 \mathrm{wt} \%$ MWCNTs). For this, both series of composites were prepared by the ultrasonic dispersion method using the same conditions of solvent, dilution, and sonication time. It was shown that, tailoring the polymer matrix with groups rich in nonpolar electric density, as diacetylene, and capable of interacting by van der Waals forces, it is possible to improve the dispersion of carbon nanotubes (CNTs) without necessity of some modification knowing that those treatments usually affect lowering their electrical properties.
\end{abstract}

\section{Introduction}

Carbon nanotubes (CNTs) have excellent electrical and mechanical properties $[1,2]$, which makes them ideal candidates for several applications, for example, as nanofiller material in conductive polymeric compounds [3]; CNTs are quite effective compared to carbon black microparticles, due to the large aspect ratio. Incorporation of CNTs into polymeric compounds gives rise to new opportunities for electronic applications, for example, in conductive films [4, 5], photovoltaic devices [6], or sensors [7-9]. Their advantages are that they may be flexible, easy to mold, and cheap; nonetheless they have the drawbacks of the polymers from fossil sources. In this context, polymers from natural sources, for example, from vegetable oils, represent a good alternative for the cost, environment, and chemical transformation, making them tailored structures [10-12]. As an example, linseed oil is a triglyceride consisting of three fatty acids condensed onto a glycerol unit; its composition is mainly of linolenic acid (56.6\%), linoleic acid (15.3\%), and oleic acid (19.1\%) moieties [13] (Figure 1), so it has on average 6.4 double bonds per triglyceride unit [14]; this feature makes it easy to modify by chemical conversion to other functional groups as epoxides. After the epoxidation, these groups could be used as cross-linker site or could be chemically modified in order to have a specific group in their structure $[15,16]$. For an effective and reproducible utilization of CNTs in these composites, it is very important to have a good and homogeneous dispersion of the conductive particles throughout the polymer matrix. However, this is likely the main drawback owing to van der Waals forces between them along with their structure; they form clusters or tight long bundles and these might form a dense and entangled network; therefore in order to improve their dispersion, surface modifications have been made [17, 18]; one of them is the noncovalent attachment of molecules although their disadvantage is that the forces between the molecules and the CNTs might be weak; another one is the covalent attachment of functional groups to the walls of 


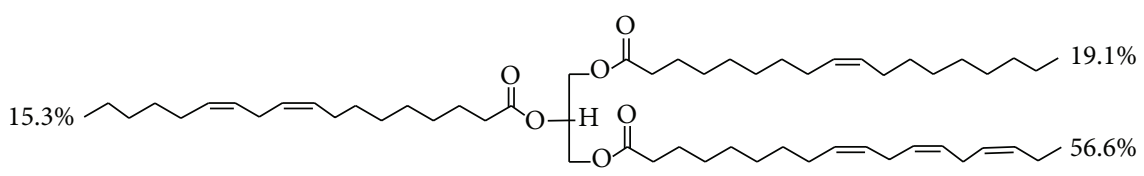

FIGURE 1: Chemical structure and main composition of linseed oil (LO).

CNTs; however this decreases the conductivity because the groups might introduce defects on the graphitic structure $[19,20]$. Functionalization with divalent adducts represents an option which alters less the electrical transport owing to unaltered $\mathrm{sp}^{2}$ conjugation [21]. Other options have been the dispersion by shear mixing, using surfactants [22], or by sonication in different solvents $[23,24]$. In order to avoid any modification to the CNT and some loss of the electrical properties, we thought in synthesizing a matrix with functional groups rich in electrical density without dipole moment, as the diacetylenes, but that it may interact with the electrical density of the CNTs via van der Waals forces, assisting the dispersion.

The proposal was the functionalization of the epoxidized linseed oil with propargyl alcohol by a catalytic ring opening reaction in order to have terminal acetylenes groups (APELO), followed by an oxidative coupling reaction C$\mathrm{C}$ to form diacetylene groups which also serve as crosslinkers of the oil. Finally, solutions of DAELO and MWCNTs at different loads were mixed using an ultrasonic bath, the percolation curve was built, and the critical concentration for diacetylene linseed oil was lower than ELO, demonstrating that rich electron groups have a positive effect on the dispersion of MWCNTs as compared with ELO.

\section{Materials and Methods}

Lipase acrylic resin from Candida antarctica, MWCNTs $D \times$ L 110-170 $\mathrm{nm} \times 5-9 \mu \mathrm{m}$, density $1.7-2.1 \mathrm{~g} / \mathrm{cm}^{3}$, linseed oil (LO), hydrogen peroxide, alumina, anhydrous zinc chlorine, propargyl alcohol (PA), copper chlorine, and tetramethyl ethylene diamine (TMEDA) were obtained from Sigma Aldrich Co.; sodium carbonate and magnesium sulphate anhydrous were obtained from J. T. Baker, Mexico. All the reactants were used as received. SEM images were obtained in a JEOL JSM-6510LV microscope at acceleration voltage of $30 \mathrm{kV}$, at 5000,10000 , and $20000 \mathrm{x}$, with backscattered electrons detector. ${ }^{1} \mathrm{H}$ NMR spectra were recorded at room temperature using $\mathrm{CDCl}_{3}$ as solvent on a Bruker Avance $300 \mathrm{MHz}$ NMR. Chemical shifts are relative to $\left(\mathrm{CH}_{3}\right)_{4} \mathrm{Si}$ and are given in ppm. FTIR-ATR spectra were recorded on an Avatar FTIR-ATR spectrophotometer, into a range between 550 and $4000 \mathrm{~cm}^{-1}$ and spectra were acquired at $4 \mathrm{~cm}^{-1}$ resolution and signals averaged over 32 scans. DSC and TGA analysis were recorded under nitrogen atmosphere $(100 \mathrm{~mL} / \mathrm{min})$ using a SDT-Q600 TA Instruments modulus from 20 to $600^{\circ} \mathrm{C}$ and heating rate of $20^{\circ} \mathrm{C} / \mathrm{min}$. Electrical resistance was measured on a digital multimeter ASYC II 5390.
ELO was synthesized using the chemoenzymatic method described in previous report [25]; a toluene solution, $100 \mathrm{~g}$ of LO, $8 \mathrm{~g}$ of oleic acid, and $10 \mathrm{~g}$ of lipase were put into a precipitate glass using $120 \mathrm{~mL}$ of solvent; the reaction mixture was warmed at $42^{\circ} \mathrm{C}$ and mixed by stirring at $355 \mathrm{rpm}$; then $160 \mathrm{~mL}$ of hydrogen peroxide at $30 \%$ drop by drop was added. After 24 hours, the reaction was filtered to recover the enzyme. The product was purified by successive extractions of $3 \times 20 \mathrm{~mL}$ of $\mathrm{Na}_{2} \mathrm{CO}_{3}$ solution at $10 \%$ and $1 \times 20 \mathrm{~mL}$ of water; finally ELO was dried using $\mathrm{MgSO}_{4}$ anhydrous. The product was characterized by FTIR-ATR, ${ }^{1} \mathrm{H}$ NMR, DSC, and TGA.

For synthesis of functionalized ELO with propargyl alcohol (PAELO), a mixture of $0.5 \mathrm{~g}$ of ELO, $\mathrm{ZnCl}_{2}$ at different percentages (5-20\%), and $0.5 \mathrm{~mL}$ of propargyl alcohol was heated at different temperatures $\left(60-90^{\circ} \mathrm{C}\right)$ and times (3$20 \mathrm{~h}$ ); a change of color was observed from white to amber or red. PA and $\mathrm{ZnCl}_{2}$ were extracted with water; the product was filtered and solved in acetone; finally it was dried by a rotary evaporator and by a vacuum line. These conditions were carried out in order to found those that render the maximal functionalization without side reactions. Products were characterized by FTIR-ATR, ${ }^{1} \mathrm{H}$ NMR, DSC, and TGA.

In order to form the diacetylene groups, a coupling $\mathrm{C}-\mathrm{C}$ of terminal acetylenes was carried out at room temperature by the Hay reaction [26, 27]. PAELO was dissolved in chloroform, while an aqueous solution of $\mathrm{CuCl}$ and TMEDA in stoichiometric ratio 1:1 was prepared; both solutions were placed together and mixed by magnetic stirring under an air flow. After $40 \mathrm{~min}$ the reaction was stopped and a solid was observed; the organic solvent was evaporated. The catalyst obtained in situ Cu(TMEDA) [28] was extracted with water many times as necessary until the characteristic blue color was not observed. The final product was a yellow solid which was dried and characterized by FTIR-ATR, DSC, TGA, and UV-Vis spectroscopy.

The diacetylene-polymer composites (DAELOMWCNTs) were prepared in three steps: first a polymer solution of $10 \mathrm{mg} / \mathrm{mL}$ in chloroform was made and MWCNTs at concentrations between 0.1 and $1.2 \mathrm{mg} / \mathrm{mL}$ were dispersed in chloroform by an ultrasonic bath for 30 minutes at $35 \mathrm{MHz}$ and $70 \mathrm{~W}$. On the second step, equal volumes were mixed and sonicated for 30 minutes more; finally $1 \mathrm{~mL}$ of the final solution was placed inside stainless steel cylinders of $14 \mathrm{~mm}$ diameter mounted on glass plates. Once the solvent was evaporated slowly (casting technique), the films were placed in an oven at $70^{\circ} \mathrm{C}$; once the samples were dried, two parallel lines of silver contacts on the surface were placed using conductive silver paint. In order to compare the effect of diacetylenes in the polymeric structure, ELOpolymer composites were made under the same conditions, 


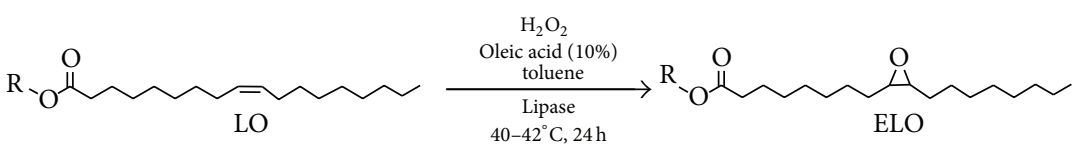<smiles>[R]OC(=O)CCCCCCC1OC1CCCCCCC[CH2+]</smiles>

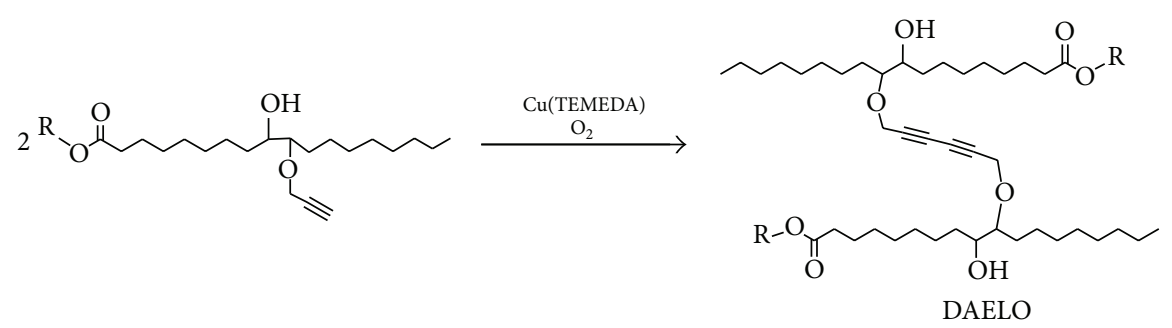

FIGURE 2: Simplified scheme for the synthesis of the polymeric matrix.

but because ELO is a liquid monomer, films of the mixture on glass substrates were cured at $220^{\circ} \mathrm{C}$ for $2 \mathrm{~h}$.

For electrical characterization, $I-V$ relationship was measured by the two-point technique with an electrometer Keithley 6717A. Samples with 1, 3, 4, 5, 8, 10, and 12\% (W/W) of MWCNTs were measured; for this polymer's MWCNTs composites, an $I-V$ lineal correlation was observed at potentials between 10 and $100 \mathrm{mV}$. The electrical resistance and the resistivity of the films were calculated and plotted against MWCNTs percentage (W/W). The thicknesses of the layers were measured using a profilometer Sloan Dektak IIA. Four samples were averaged for each point of the electrical resistance. The percolation theory was applied in order to calculate the percolation threshold, at the onset of the network; electrical resistivity obeys the power law relation:

$$
\sigma=\sigma_{m}\left(\phi-\phi_{c}\right)^{\beta},
$$

where $\sigma$ is the electrical resistivity of the polymeric compound, $\phi$ is the filler concentration, $\phi_{c}$ is the critical filler concentration or percolation threshold, and $\beta$ and $\sigma_{m}$ are fitting constant. The adjustment was made using Origin 6.0 software. Three free parameters $\sigma_{m}, \phi_{c}$, and $\beta$ were considered, where $\sigma_{m}$ is the proportionality constant. Best fitting curves were obtained for $\beta$ very close to -1.65 ; then $\beta$ was fixed to this value and numerical interactions were run again until reaching 0.99 of data correlation.

\section{Results and Discussion}

ELO was synthesized by a chemoenzymatic reaction (Figure 2). The epoxy rings formation was confirmed by FTIR-ATR, ${ }^{1} \mathrm{H}$ NMR, and DCS. By FTIR-ATR, the band at $821 \mathrm{~cm}^{-1}$ corresponding to the $\nu(\mathbf{C}-\mathbf{O})$ from epoxy groups was observed (Figure 3(b)), whereas those corresponding to the double bonds at 1650 and 3008 do not (Figure 3(a)). The ${ }^{1} \mathrm{H}$ NMR spectrum also showed the signals from epoxy

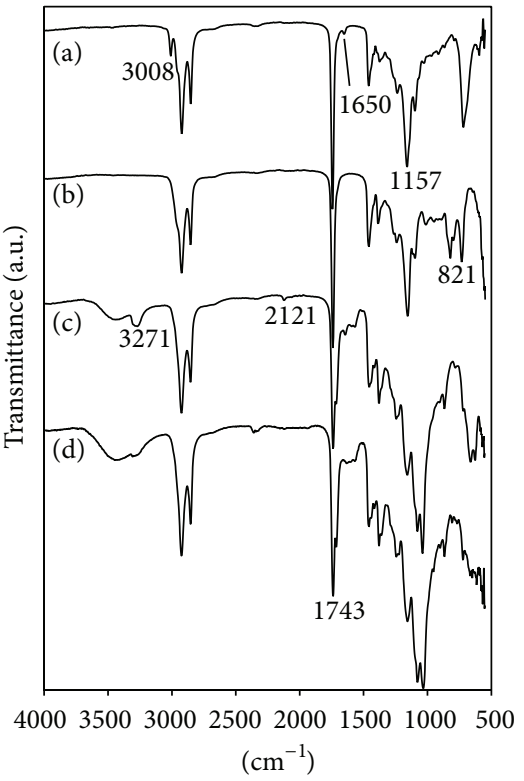

Figure 3: FTIR-ATR spectra of (a) LO, (b) ELO, (c) APELO, and (d) DAELO.

rings between 2.90 and $3.21 \mathrm{ppm}$, integrating 11.5 hydrogens (Figure 4(b)); these signals allowed calculating the epoxy groups percentage; it was $96 \%$ with respect to the signals from the double bonds between 5.23 and $5.42 \mathrm{ppm}$ in the ${ }^{1} \mathrm{H}$ NMR spectrum of LO integrating 12 hydrogens (Figure 4(a)). The signal of hydrogens from double bonds in the ELO spectrum integrates only 0.56 . Molecular weight of LO and ELO was calculated by integration of their respective spectra; for the first one it was $879 \mathrm{~g} / \mathrm{mol}$ and for the second one it was $970 \mathrm{~g} / \mathrm{mol}$. In DSC an exothermic peak between 205 and $275^{\circ} \mathrm{C}$ was observed which corresponds to the ring opening of epoxy groups (Figure 5(a)) [29]. 


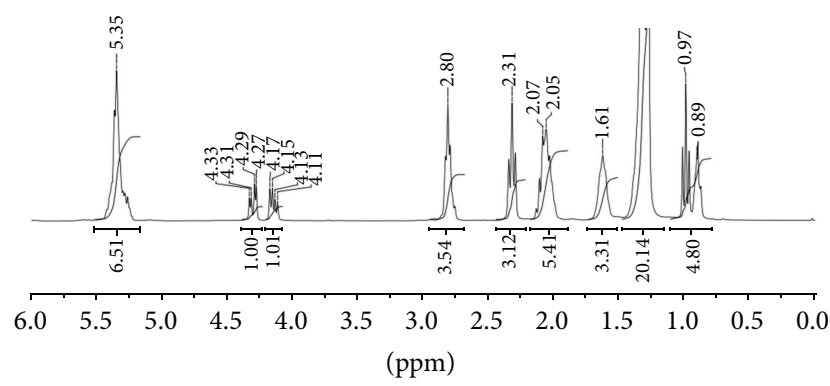

(a)

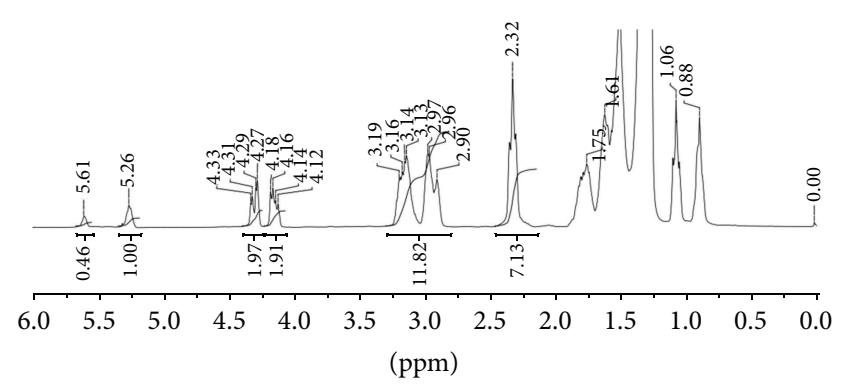

(b)

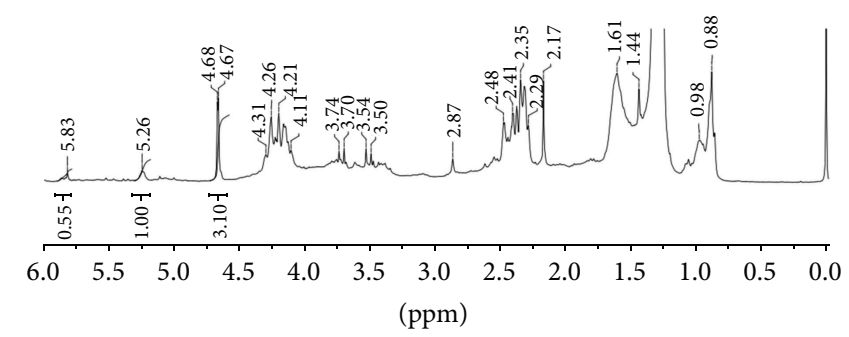

(c)

Figure $4:{ }^{1} \mathrm{H}$ NMR $300 \mathrm{MHz}, \mathrm{CDCl}_{3}$ of (a) LO, (b) ELO, and (c) APELO.

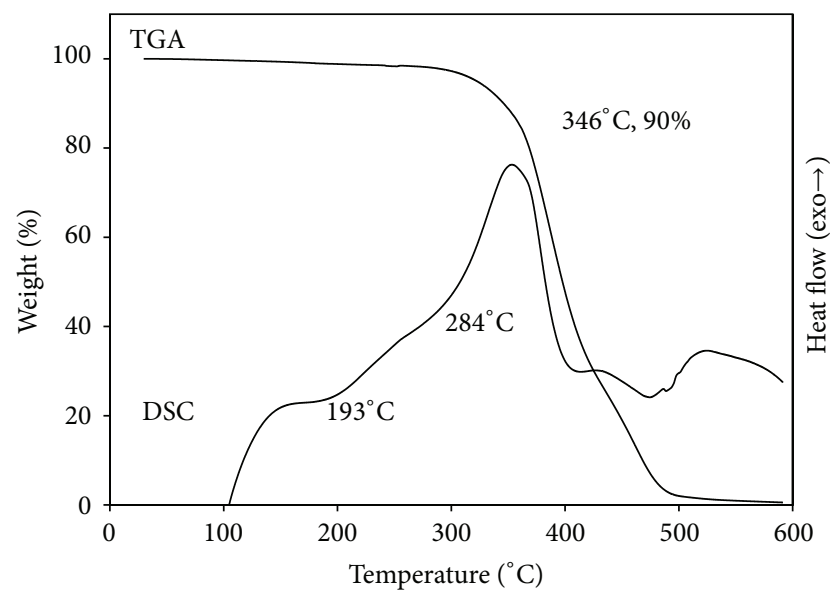

(a)

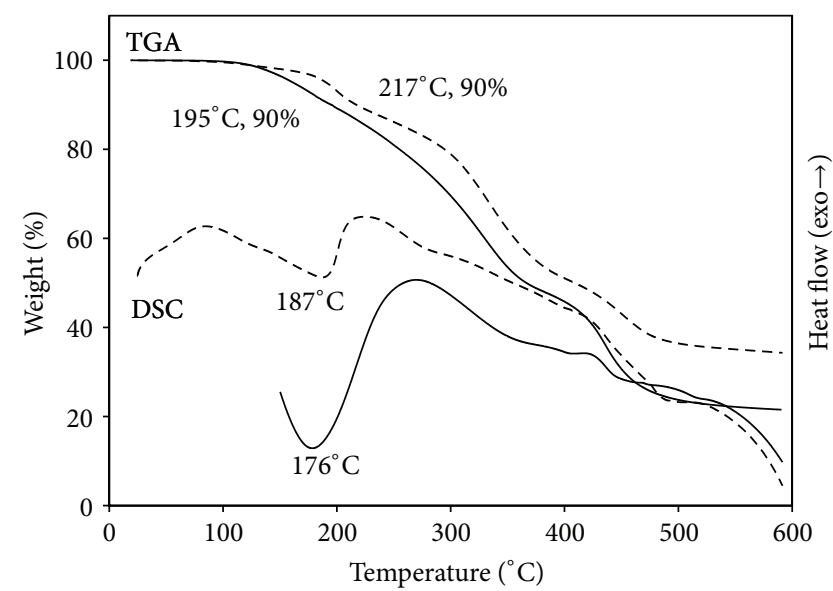

(b)

FIgURE 5: DSC and TGA runs of (a) ELO and (b) APELO (solid lines) and DAELO (dashed lines). Heating rate of $20^{\circ} \mathrm{C} / \mathrm{min}$ under nitrogen atmosphere.

ELO was functionalized with PA by an epoxy ring opening reaction catalyzed by $\mathrm{ZnCl}_{2} ; \mathrm{PA}$ was used as reactant and solvent in order to obtain better results. The higher percent of functionalization (27\%) was obtained when the reaction was carried out at $80^{\circ} \mathrm{C}, 20 \mathrm{~h}$, and 20 mol percent of catalyst. The products were characterized by FTIR-ATR and ${ }^{1} \mathrm{H}$ NMR. In the FTIR-ATR spectra the bands of $\nu(\mathrm{C} \equiv \mathbf{C}-\mathbf{H})$ at $3271 \mathrm{~cm}^{-1}$ and $\nu(\mathbf{C} \equiv \mathbf{C})$ at $2121 \mathrm{~cm}^{-1}$ were observed as well as the characteristic band centered around $3450 \mathrm{~cm}^{-1}$ from hydroxyl groups (Figure 3(c)); the band from epoxy groups was not observed. On the other hand, in the ${ }^{1} \mathrm{H}$ NMR spectrum of APELO, the signal of methylene from PA appeared as a doublet at $4.68 \mathrm{ppm} ; J=3 \mathrm{~Hz}$ (Figure 4(c)); the integration allowed calculating the percent of functionalization with respect to the epoxy groups; for the highest functionalization (28\%) the integral had a value of 3.20 , corresponding to 1.6 acetylene groups. When the reaction was carried out for only $5 \mathrm{~h}$, the functionalization was of $26 \%$; therefore, these conditions were used for the APELO synthesis. Results for other conditions are shown in Table 1. Low values should be due to hydroxyl group formation which attack epoxy rings to form ethers. This is evidenced by IR (Figure 3), where the band of $\nu(\mathbf{C}-\mathbf{O})$ at $1037 \mathrm{~cm}^{-1}$ is more intense than in ELO and LO spectra.

Cross-linking of acetylenes of PAELO was carried out by the Hay reaction. The product obtained (DAELO) was 


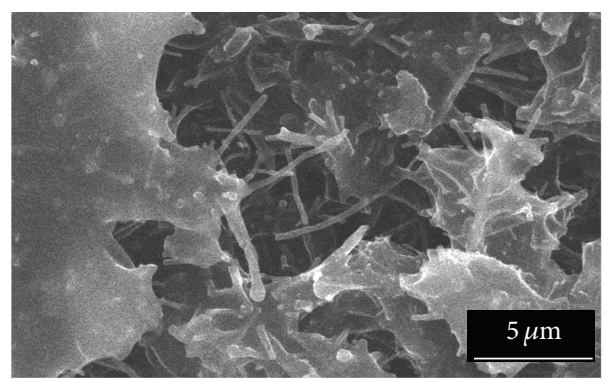

(a)

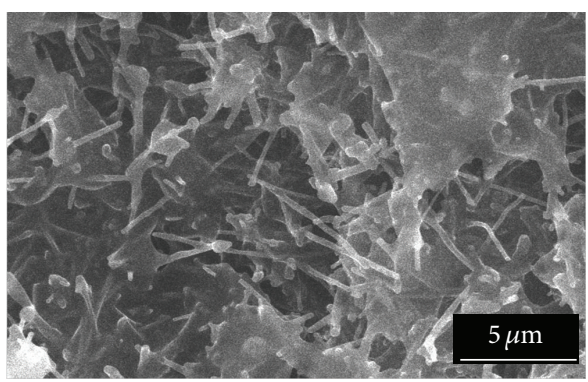

(b)

FIGURE 6: SEM micrographs of polymeric composites with (a) 5\% and (b) 10\% of MWCNTs, $30 \mathrm{kV}$, and 5000x.

TABLE 1: Results of the functionalization of ELO with PA at different conditions.

\begin{tabular}{lccc}
\hline $\begin{array}{l}\text { Catalyst } \\
(\%)\end{array}$ & $\begin{array}{c}\text { Reaction } \\
\text { time }\end{array}$ & $\begin{array}{c}\text { Temperature } \\
\left({ }^{\circ} \mathrm{C}\right)\end{array}$ & $\begin{array}{c}\text { Functionalization } \\
(\%)\end{array}$ \\
\hline 10 & 5 & 80 & 8 \\
20 & 3 & 80 & 19 \\
20 & 5 & 80 & 26 \\
20 & 20 & 80 & 27 \\
20 & 5 & 70 & 22 \\
20 & 8 & 70 & 20 \\
30 & 5 & 70 & 20 \\
\hline
\end{tabular}

a yellow solid which was characterized by FTIR-ATR, DSC, and TGA. In FTIR, the band of $\nu(C \equiv \mathbf{C}-\mathbf{H})$ at $3270 \mathrm{~cm}^{-1}$ diminished with respect to PAELO which confirm the CC coupling (Figure 3(d)). This coupling improves thermal stability as shown by TGA (Figure 5(b)). The $T_{10}$ for DAELO was $216^{\circ} \mathrm{C}$, whereas for PAELO it was $154^{\circ} \mathrm{C}$. In DSC an exothermic peak starts at 176 and $187^{\circ} \mathrm{C}$ for PAELO and DAELO, respectively, owing to their corresponding decomposition.

Once the resin is obtained, the polymeric compounds were prepared according to the experimental section. Chloroform was chosen as solvent due to the fact that it has been used at high MWCNTs concentrations [30]. Interestingly, only one hour of ultrasound was enough to disperse the MWCNTs inasmuch as longer times might cause fractures on CNTs [24]. Dispersion was confirmed by images from SEM (Figure 6) for samples with 5 and $10 \%$ at 5000x.

The electrical resistance of DAELO-MWCNTs compounds was measured for samples with $1,3,4,5,8,10$, and $12 \%$ (W/W) of MWCNTs at potentials between 10 and $100 \mathrm{mV}$; in all cases a lineal relation was obtained, indicating an adequate electric contact between the network of MWCNTs and a very good distribution of them in the matrix. It is also noted that a good tendency of resistivity is obtained in the limits of the percolation theory; this is difficult to reach for other particles if the synthesis conditions are not optimized. Resistivity values are shown in Figure 7; these

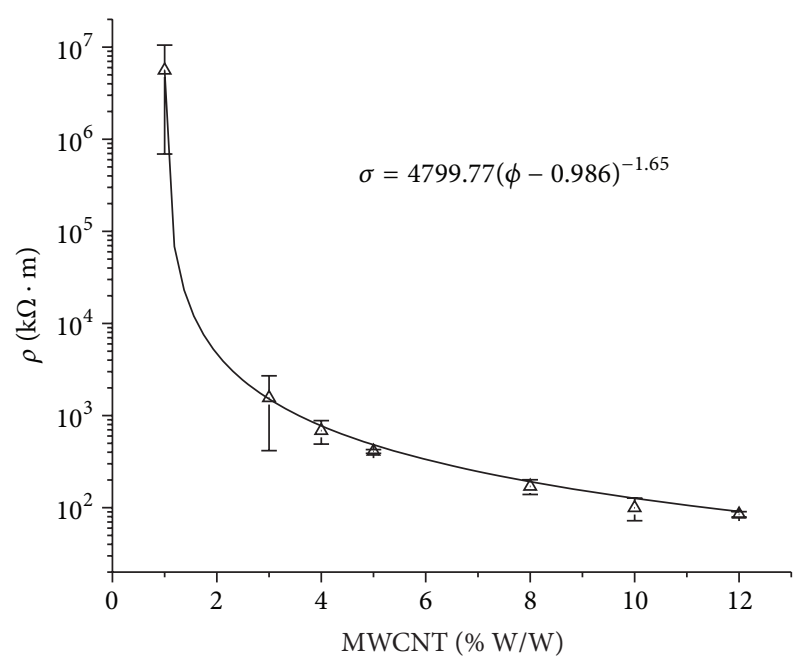

FIGURE 7: Resistivity as a function of MWCNTs percentage (W/W), mean value $\pm \mathrm{SD}(n=4)$, and their adjusted curve.

were adjusted by percolation threshold equation finding the critical concentration at $0.99 \%$ (W/W) which is similar to other polymer MWCNTs compounds; for example, the percolation threshold for polystyrene-single walled carbon nanotubes composites was at $1.5 \%$ (W/W) [31], whereas for polyvinylidene fluoride MWCNTs it was at 0.95\% [32]. Although the density of DAELO was slightly lower than ELO, the volumetric fraction of MWCNTs was similar in both compounds. In comparison, the measured compositions of ELO-composites always had a higher value of resistivity and a higher error, indicating a major problem of dispersion of CNTs in that molecule; even if it is true, the resistivity of ELO without CNTs is higher than DAELO; results are given in Table 2 . This result could be explained in terms of $\pi$ interactions between the electrical density of diacetylenes groups (1 per molecule in average) and electrical density of MWCNTs allowing a better dispersion [33]. By tailoring the polymer matrix, it is possible to improve the interactions between the electronic density of the functional groups in the polymers and the CNTs reaching a low critical concentration in the electrical conductive composites. 
TABLE 2: Comparison of resistivity of composites at different percentage of MWCNTs.

\begin{tabular}{lcc}
\hline $\begin{array}{l}\text { MWCNTs } \\
(\mathrm{W} / \mathrm{W})\end{array}$ & $\begin{array}{c}\rho(\mathrm{k} \Omega \cdot \mathrm{m}) \\
\text { DAELO-MWCNTs }\end{array}$ & $\begin{array}{c}\rho(\mathrm{k} \Omega \cdot \mathrm{m}) \\
\text { ELO-MWCNTs }\end{array}$ \\
\hline 0 & $7.1 \times 10^{7}$ & $1.7 \times 10^{9}$ \\
1 & $9.08 \times 10^{6} \pm 4.9 \times 10^{6}$ & - \\
3 & $1559 \pm 1143$ & - \\
4 & $686 \pm 196$ & - \\
5 & $408 \pm 19$ & $4697 \pm 1642$ \\
8 & $170 \pm 31$ & $5711 \pm 3658$ \\
10 & $99.7 \pm 27.5$ & $3160 \pm 944$ \\
12 & $81.6 \pm 5.7$ & $3101 \pm 1392$ \\
\hline
\end{tabular}

Densities of ELO, DAELO, and MWCNTs were $0.99,0.89$, and $1.9 \mathrm{~g} / \mathrm{cm}^{3}$, respectively.

\section{Conclusions}

In this work, the functionalization of ELO with PA was only $27 \%$; however it was possible to make a resin by oxidative coupling of the terminal alkynes; this resin was used as matrix for the polymer MWCNTs composites formation where the introduction of a few diacetylenes groups allows the dispersion of MWCNTs with a short time of sonication. The percolation threshold was at low concentration of conductive particles; these decreased the electrical resistivity in five orders of magnitude from $1 \%$ to $10 \%$ in weight of MWCNTs. Because the combination of CNTs and polymers with $\pi$ electrons had been of interest for electronic devices, we think that these composites may have potential application, for example, in vapor sensors.

\section{Conflict of Interests}

The authors declare that there is no conflict of interests regarding the publication of this paper.

\section{Acknowledgments}

The authors are grateful to the Universidad Autónoma del Estado de México for the support under Project 3540/2013 CHT and to the CONACyT for the fellowship for the postdoctoral stance of Ph.D. Alejandro Ramírez-Jiménez. The authors thank M. C. Maria de las Nieves Zavala Segovia, Ph.D. Gustavo López-Tellez from CCIQS UAEM-UNAM, and M. S. Alejandro Esparza from CECADET-UNAM for their technical support with NMR, SEM analysis, and thickness measurements, respectively.

\section{References}

[1] P. G. Collins, A. Zettl, H. Bando, A. Thess, and R. E. Smalley, "Nanotube nanodevice," Science, vol. 278, no. 5335, pp. 100-103, 1997.

[2] E. T. Thostenson, Z. Ren, and T.-W. Chou, "Advances in the science and technology of carbon nanotubes and their composites: a review," Composites Science and Technology, vol. 61, no. 13, pp. 1899-1912, 2001.

[3] R. H. Baughman, A. A. Zakhidov, and W. A. de Heer, "Carbon nanotubes the route toward applications," Science, vol. 297, no. 5582, pp. 787-792, 2002.

[4] T. Sekitani, H. Nakajima, H. Maeda et al., "Stretchable activematrix organic light-emitting diode display using printable elastic conductors," Nature Materials, vol. 8, no. 6, pp. 494-499, 2009.

[5] L. Hu, M. Pasta, F. La Mantia et al., "Stretchable, porous, and conductive energy textiles," Nano Letters, vol. 10, no. 2, pp. 708$714,2010$.

[6] H. Ago, K. Petritsch, M. S. P. Shaffer, A. H. Windle, and R. H. Friend, "Composites of carbon nanotubes and conjugated polymers for photovoltaic devices," Advanced Materials, vol. 11, no. 15, pp. 1281-1285, 1999.

[7] A. Merkoçi, M. Pumera, X. Llopis, B. Pérez, M. Del Valle, and S. Alegret, "New materials for electrochemical sensing VI: carbon nanotubes," Trends in Analytical Chemistry, vol. 24, no. 9, pp. 826-838, 2005.

[8] W. Obitayo and T. Liu, "A review: carbon nanotube-based piezoresistive strain sensors," Journal of Sensors, vol. 2012, Article ID 652438, 15 pages, 2012.

[9] N. Sinha, J. Ma, and J. T. W. Yeow, "Carbon nanotube-based sensors," Journal of Nanoscience and Nanotechnology, vol. 6, no. 3, pp. 573-590, 2006.

[10] U. Biermann, U. Bornscheuer, M. A. R. Meier, J. O. Metzger, and H. J. Schäfer, "Oils and fats as renewable raw materials in chemistry," Angewandte Chemie, vol. 50, no. 17, pp. 3854-3871, 2011.

[11] M. A. Mosiewicki and M. I. Aranguren, "A short review on novel biocomposites based on plant oil precursors," European Polymer Journal, vol. 49, no. 6, pp. 1243-1256, 2013.

[12] G. Lligadas, J. C. Ronda, M. Galià, and V. Cádiz, "Renewable polymeric materials from vegetable oils: a perspective," Materials Today, vol. 16, no. 9, pp. 337-343, 2013.

[13] L. Montero de Espinosa and M. A. R. Meier, "Plant oils: the perfect renewable resource for polymer science?!" European Polymer Journal, vol. 47, no. 5, pp. 837-852, 2011.

[14] Y. Xia, R. L. Quirino, and R. C. Larock, "Bio-based thermosetting polymers from vegetable oils," Journal of Renewable Materials, vol. 1, no. 1, pp. 3-27, 2013.

[15] A. Köckritz and A. Martin, "Oxidation of unsaturated fatty acid derivatives and vegetable oils," European Journal of Lipid Science and Technology, vol. 110, no. 9, pp. 812-824, 2008.

[16] R. Andrews and M. C. Weisenberger, "Carbon nanotube polymer composites," Current Opinion in Solid State \& Materials Science, vol. 8, no. 1, pp. 31-37, 2004.

[17] A. Eitan, K. Jiang, D. Dukes, R. Andrews, and L. S. Schadler, "Surface modification of multiwalled carbon nanotubes: toward the tailoring of the interface in polymer composites," Chemistry of Materials, vol. 15, no. 16, pp. 3198-3201, 2003.

[18] N. Roy, R. Sengupta, and A. K. Bhowmick, "Modifications of carbon for polymer composites and nanocomposites," Progress in Polymer Science, vol. 37, no. 6, pp. 781-819, 2012.

[19] J. E. Moreno-Marcelino, E. Vigueras-Santiago, G. López-Téllez, and S. Hernández-López, "Chemical functionalization of carbon nanotubes and its effects on electrical conductivity," Journal of Nano Research, vol. 28, pp. 51-61, 2014.

[20] A. López-Bezanilla, F. Triozon, S. Latil, X. Blase, and S. Roche, "Effect of the chemical functionalization on charge transport in 
carbon nanotubes at the mesoscopic scale," Nano Letters, vol. 9, no. 3, pp. 940-944, 2009.

[21] D. Bouilly, J. Cabana, and R. Martel, "Unaltered electrical conductance in single-walled carbon nanotubes functionalized with divalent adducts," Applied Physics Letters, vol. 101, no. 5, Article ID 053116, 2012.

[22] J. Yu, N. Grossiord, C. E. Koning, and J. Loos, "Controlling the dispersion of multi-wall carbon nanotubes in aqueous surfactant solution," Carbon, vol. 45, no. 3, pp. 618-623, 2007.

[23] K. D. Ausman, R. Piner, O. Lourie, R. S. Ruoff, and M. Korobov, "Organic solvent dispersions of single-walled carbon nanotubes: toward solutions of pristine nanotubes," Journal of Physical Chemistry B, vol. 104, no. 38, pp. 8911-8915, 2000.

[24] Y. Y. Huang and E. M. Terentjev, "Dispersion of carbon nanotubes: mixing, sonication, stabilization, and composite properties," Polymers, vol. 4, no. 1, pp. 275-295, 2012.

[25] G. López-Tellez, E. Vigueras-Santiago, and S. HernándezLópez, "Characterization of linseed oil epoxidized at different percentages," Superficies y Vacío, vol. 22, no. 1, pp. 5-10, 2009.

[26] A. S. Hay, "Oxidative coupling of acetylenes. $\mathrm{II}^{1}$," The Journal of Organic Chemistry, vol. 27, no. 9, pp. 3320-3321, 1962.

[27] B. Maaten, J. Moussa, C. Desmarets et al., "Cu-modified hydroxy-apatite as catalyst for Glasser-Hay C-C homo-coupling reaction of terminal alkynes," Journal of Molecular Catalyst A: Chemical, vol. 393, pp. 112-116, 2014.

[28] P. Lahtinen, E. Lankinen, M. Leskelä, and T. Repo, "Insight into copper oxidation catalysts: kinetics, catalytic active species and their deactivation," Applied Catalysis A: General, vol. 295, no. 2, pp. 177-184, 2005.

[29] G. López Téllez, E. Vigueras-Santiago, S. Hernández-López, and B. Bilyeu, "Synthesis and thermal cross-linking study of partially-aminated epoxidized linseed oil," Designed Monomers and Polymers, vol. 11, no. 5, pp. 435-445, 2008.

[30] C.-X. Liu and J.-W. Choi, "Improved dispersion of carbon nanotubes in polymers at high concentrations," Nanomaterials, vol. 2, no. 4, pp. 329-347, 2012.

[31] V. Antonucci, G. Faiella, M. Giordano, L. Nicolais, and G. Pepe, "Electrical properties of single walled carbon nanotube reinforced polystyrene composites," Macromolecular Symposia, vol. 247, pp. 172-181, 2007.

[32] R. Rizvi and H. E. Naguib, "Carbon nanotube network evolution during deformation of PVDF-MWNT nanocomposites," in Electroactive Polymer Actuators and Devices, vol. 8687 of Proceedings of SPIE, International Society for Optics and Photonics, San Diego, Calif, USA, March 2013.

[33] X. Dai, Z. Liu, B. Han et al., "Carbon nanotube/poly(2,4hexadiyne-1,6-diol) nanocomposites prepared with the aid of supercritical $\mathrm{CO}_{2}$," Chemical Communications, vol. 10, no. 19, pp. 2190-2191, 2004. 

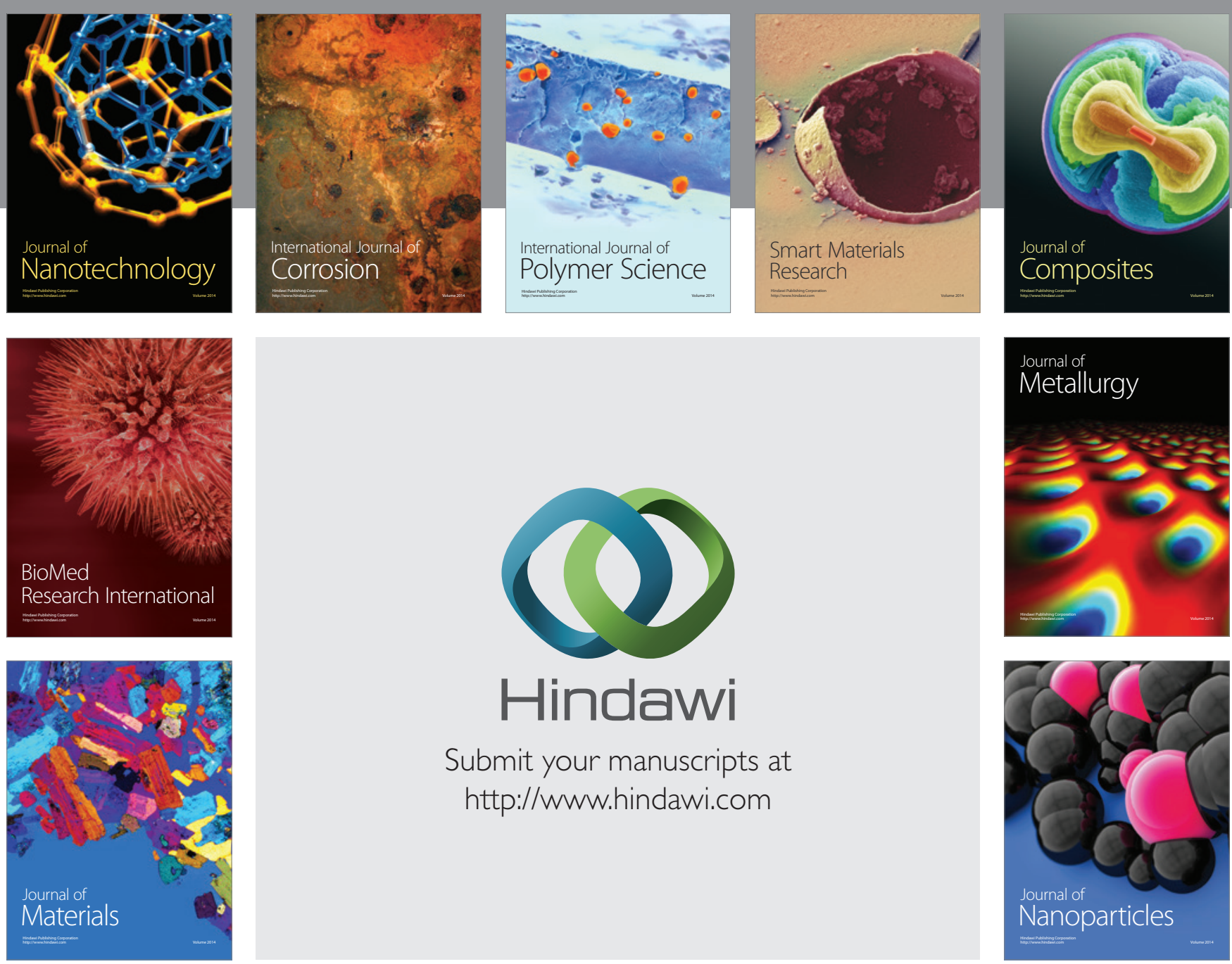

Submit your manuscripts at http://www.hindawi.com
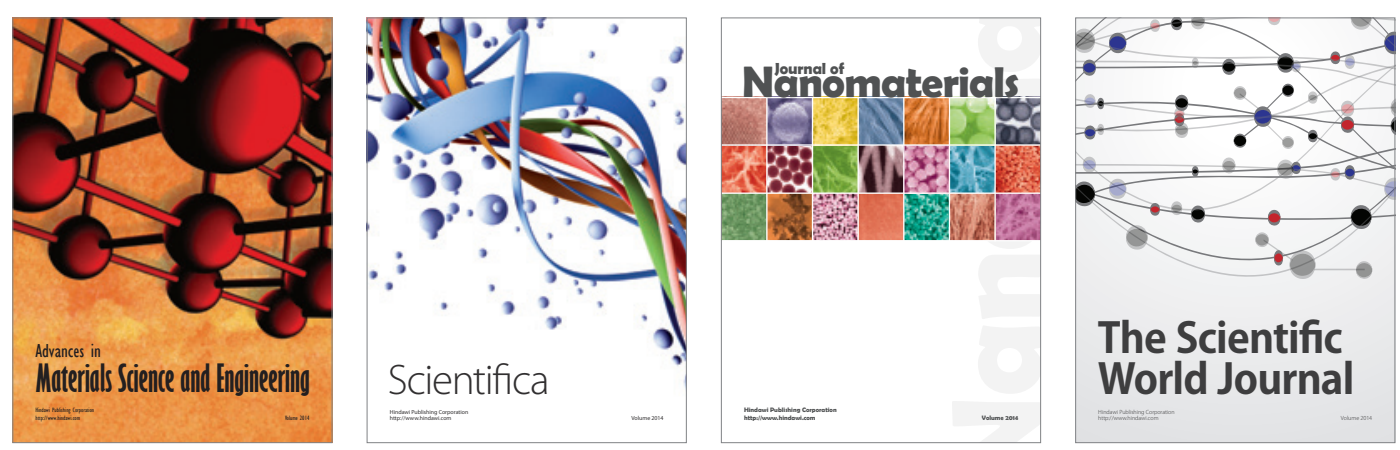

\section{The Scientific World Journal}
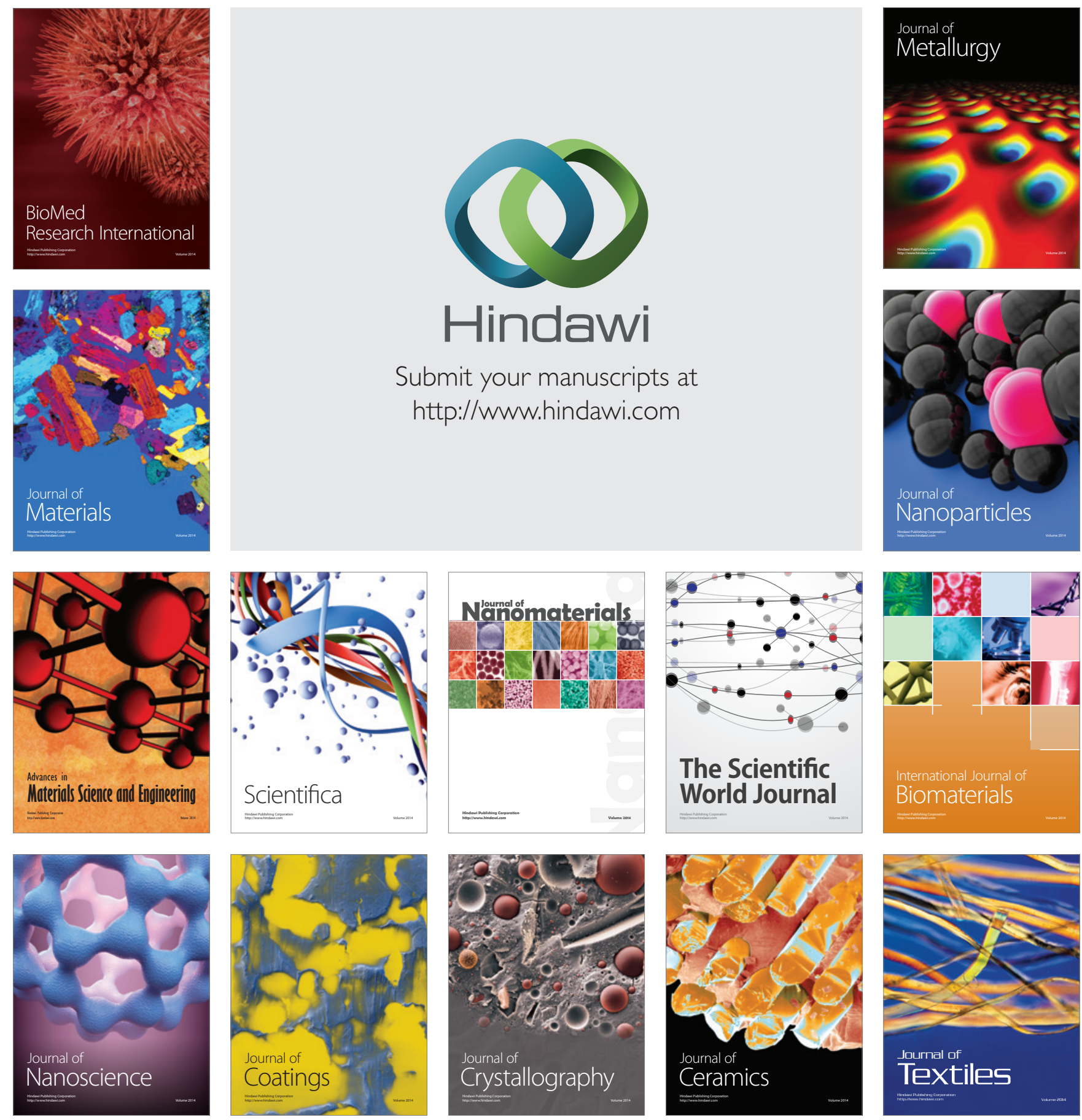